\title{
Family, Maternal, and Child Health Through Photovoice
}

\author{
Caroline C. Wang, DrPH, MPH ${ }^{1,3}$ and Cheri A. Pies, MSW, DrPH ${ }^{2,3}$
}

Objective: (1) To introduce photovoice, a participatory action research methodology, for use by $\mathrm{MCH}$ program managers to enhance community health assessments and program planning efforts, (2) to enable community people to use the photovoice methodology as a tool to record, reflect, and communicate their family, maternal, and child health assets and concerns, and (3) to educate community leaders about family, maternal, and child health issues from a grassroots perspective. Methods: Photovoice is based upon the theoretical literature on education for critical consciousness, feminist theory, and community-based approaches to documentary photography. Picture This Photovoice project took place in Contra Costa, an economically and ethnically diverse county in the San Francisco Bay area. Sixty county residents of ages 13-50 participated in 3 sessions during which they received training from the local health department in the techniques and process of photovoice. Residents were provided with disposable cameras and were encouraged to take photographs reflecting their views on family, maternal, and child health assets and concerns in their community, and then participated in group discussions about their photographs. Community events were held to enable participants to educate $\mathrm{MCH}$ staff and community leaders. Results: The photovoice project provided $\mathrm{MCH}$ staff with information to supplement existing quantitative perinatal data and contributed to an understanding of key $\mathrm{MCH}$ issues that participating community residents would like to see addressed. Participants' concerns centered on the need for safe places for children's recreation and for improvement in the broader community environment within county neighborhoods. Participants' definitions of family, maternal, and child health assets and concerns differed from those that $\mathrm{MCH}$ professionals may typically view as MCH issues (low birth weight, maternal mortality, teen pregnancy prevention), which helped MCH program staff to expand priorities and include residents' foremost concerns. Conclusions: $\mathrm{MCH}$ professionals can apply photovoice as an innovative participatory research methodology to engage community members in needs assessment, asset mapping, and program planning, and in reaching policy makers to advocate strategies promoting family, maternal, and child health as informed from a grassroots perspective.

KEY WORDS: maternal and child health; photovoice; participatory; health department; needs assessment; policy makers.

\section{INTRODUCTION}

Every 5 years, each State Maternal and Child Health $(\mathrm{MCH})$ agency in the United States is required to conduct a needs assessment as part of its application for Title V MCH federal block grant funds, and to develop a 5-year plan for addressing MCH needs.

\footnotetext{
${ }^{1}$ Department of Health Behavior and Health Education, School of Public Health, University of Michigan, Ann Arbor, Michigan.

${ }^{2}$ Family, Maternal, and Child Health Programs, Contra Costa Health Services, Martinez, California.
}

State $\mathrm{MCH}$ agencies require local health jurisdictions (i.e., counties and cities) to conduct a needs assessment and develop a plan that is then used to prepare the State Title V application. Local MCH programs

\footnotetext{
${ }^{3}$ Correspondence should be addressed to Dr. Caroline C. Wang, School of Public Health/HBHE, University of Michigan, 1420 Washington Heights, Ann Arbor, Michigan 48109-2029; e-mail: wangc@umich.edu; or to Dr. Cheri A. Pies, Director, Family, Maternal and Child Health Programs, 597 Center Avenue, Suite 365, Martinez, California 94553; e-mail: cpies@hsd.co.contracosta.ca.us
} 
have historically relied on a range of data sources for the assessment and development of their 5-year local plans. Such data sources tend to be epidemiologic in nature, highlighting MCH health status and outcomes, performance measures, and health indicators. Absent from these sources, however, is the firsthand knowledge and experience of low-income residents, non-English speakers, and others most likely to bear the greatest burden of poor family, maternal, and child health. We describe the application of an innovative methodology, photovoice, that creates an opportunity for $\mathrm{MCH}$ program staff, providers, administrators, planners, and evaluators to supplement the $\mathrm{MCH}$ data gathering and planning process with the perspectives and ideas of community residents.

\section{BACKGROUND ON PHOTOVOICE}

Photovoice is a process in which people (1) photograph their everyday health and work realities, (2) participate in group discussions about their photographs, thereby higlighting personal and community issues of greatest concern, and (3) reach policy makers, health planners, community leaders, and other people who can be mobilized to make change $(1,2)$. Its theoretical underpinnings are provided by Paulo Freire's approach to education for critical consciousness, feminist theory, and a community-based approach to documentary photography. $(1,3)$

Freire's work highlights the importance of people's sharing and speaking from their own experience, seeing connections among their individual situations, creating an analytical perspective from which to relate their situations to root causes, and developing solutions and strategies for change $(4,5)$. Feminist theory holds that power accrues to those who have voice, set language, make history, and participate in decisions (6). By creating photographs and narratives that provide a language to influence decisions, participants can use photovoice to enhance their public presence. Finally, participatory approaches to documentary photography developed by Ewald $(7,8)$, Hubbard (9), Spence (10), and other activist photographers (11) suggest a grassroots approach to representation, and demonstrate ways in which a variety of populations can use photography as personal voice.

The photovoice concept, and its application for conducting participatory needs assessment, assetmapping, and evaluation, and reaching policy mak- ers, have been discussed elsewhere (1-3, 12-21). Photovoice has been used by Chinese village women promoting reproductive health $(1-3,12-14)$, young mothers and grandmothers establishing crossgenerational links in Detroit (17), Black and Latino youth drawing attention to the AIDS epidemic in the San Francisco Bay area (18), and many others $(15,16$, 19-21). Five key concepts are intended to unite the ways in which diverse groups apply the photovoice technique. These concepts include the understanding that 1) images teach; 2) photographs can influence programs and policy; 3) community people ought to participate in creating and defining the images that shape healthful public policy; 4) the process requires that from the outset planners bring to the table policy makers and other influential people to serve as an audience for community people's perspectives; and 5) photovoice emphasizes individual and community action (2).

\section{METHODS}

Picture This Photovoice was initiated by a Family, Maternal, and Child Health program of a county health department. The project took place in Contra Costa, a large, economically, geographically, and ethnically diverse county in northern California. With over 950,000 residents, Caucasians make up $58 \%$ of the population, Latinos $18 \%$, Asian/Pacific Islanders $11 \%$, African Americans 9\%, and multiracial others 4\%. In 1999, Contra Costa recorded 12,538 births, with the proportion of births to Hispanic and Asian/Pacific Islander women rising significantly more compared to Caucasian and African American women.

The county has identified that the poorest perinatal outcomes (low birth weight births, infant mortality, late or no entry into care, and births to teens) are concentrated in five zip code areas where $25 \%$ of the county population resides. In these areas, $56 \%$ of all county births to teens occur, $48 \%$ of women receive no or late prenatal care, and $35 \%$ of low birth weight births occur. Forty-three percent of the residents in these areas have no high school education and $53 \%$ of the households are receiving public assistance (22).

Given the poor perinatal outcomes in these five zip code areas, $\mathrm{MCH}$ staff designed a photovoice project to gather qualitative data to help identify family, maternal, and child concerns of community 
residents. Participants would describe issues needing health department attention. To this end, an attractive flyer was developed and distributed throughout these five zip code areas advertising the Picture This project. Public Health Nurses gave flyers out at the county clinics and on home visits. Community outreach workers posted flyers in community centers, WIC centers, child care centers, children's health and social services locations, and community-based organizations such as Battered Women's Alternatives, Center for $\mathrm{Hu}$ man Development, East Bay Perinatal Council, local preschools, and laundromats. Sixty participants were recruited for this project. The authors and a social work graduate student served as project and group discussion facilitators.

Over a 5-month period, two Picture This sessions were held in different areas of the county. Each session consisted of three 3-hour workshops. At the first workshops, participants received training in the goals and methods of Picture This Photovoice. At the next two workshops, participants were divided into discussion groups. At the end of each workshop, all participants completed written evaluations and received a cash stipend or a gift certificate to local supermarkets. We detail workshop session content below.

The first session was held in the section of Contra Costa County known as east county (drawing residents from the cities of Bay Point, Pittsburg, and Antioch), and the second session was in west county (drawing residents from the cities of Richmond, North Richmond, and San Pablo). To accommodate participants' parenting and work schedules, each 3-h workshop was held in the evening and included dinner. Participants ranged in age from 13 to 50, with close to $50 \%$ African American, $40 \%$ Caucasian, and $10 \%$ Hispanic. Most of the participants came from neighborhoods in the five zip code areas in the county identified as having poorest perinatal outcomes. More than 40 participants, and an additional 20 children, participated in the first workshop session. Once people had eaten dinner and the children were placed in childcare, participants viewed a slide presentation about photovoice: its origins, the concept, and its application to promoting family, maternal, and child health. Workshop facilitators described how groups such as rural women in China and people living in a shelter in Ann Arbor used the photovoice methodology to document community issues and to reach policy makers.

Wang and Redwood-Jones note ethical issues related to photovoice participants' safety and po- tential for invasion of privacy of those they photograph. They provide recommendations (23) to minimize risks. After the slide presentation, participants asked questions, discussed the use of cameras, issues of power when taking photographs, and the ethics of taking pictures of people in the community. Workshop facilitators posed the following questions for discussion: What responsibilities does one have when using a camera? What is an acceptable way to approach someone when you want to take his or her picture? What types of situations or images would you want to avoid capturing in a photograph? The purpose of this discussion was to focus participants' attention on ways to minimize risks when taking photographs in the community, be it physical danger or loss of privacy to themselves and their community (23).

Each person signed a consent form indicating they would share their photographs and work in partnership with the county health department to improve the health of families, mothers, and children of the county. The health department purchased disposable cameras with 27 exposures and a flash. Each participant was provided with a camera and encouraged to take one or two self-portraits, to help identify exposed film in case any mix-up of film occurred. Each person also received a stamped enveloped addressed to the health department photovoice coordinator, and was asked to mail their camera for processing on a particular date, thereby giving them several days to take pictures.

Participants were asked to photograph people, places, and things that could convey their perspectives on family, maternal, and child health issues in their community, including problems and strengths. As Minkler notes, "In their classic indictment of traditional 'needs-based' approaches to health and human welfare, Kretzmann and McKnight (1993) argue that well-meaning professionals and bureaucracies frequently hurt communities by characterizing them as 'bundles of pathologies' or problems to be solved" (24). To help prepare participants for taking photographs, we asked them to brainstorm and discuss ways to photograph family, maternal, and child health issues requiring attention, as well as to find and document community assets. Participants offered examples of ideas that would tell a story to illustrate their concerns, such as children finding discarded needles where they play, gang turf-marking with graffiti, and youth centers needing community support. They also discussed community resources that could 
help address these issues. In this way participants used photovoice in a dual fashion: as a tool to assess needs and, in line with John Kretzmann's and John McKnight's innovation for mobilizing community strengths, as a tool to map assets and resources in the community $(1,25)$.

All individuals who attended this first workshop returned their cameras within the allotted time period and health department staff had the film developed. For each disposable camera, two sets of prints were developed. Participants received one set, and health department staff kept the other set.

The next two workshop sessions followed a similar format wherein participants were divided into three discussion groups. Each participant received his or her color prints and a handout describing the photovoice concept, and was then asked to select one or two photographs that he or she felt were the most significant, or simply liked best. The discussion was set around the mnemonic SHOWeD (2): What do you See here? What's really Happening here? How does this relate to Our Lives? Why does this problem, concern, or strength exist? What can we Do about it? Participants took turns describing their photographs. As the participants told the story of their photograph, with others asking questions, health department staff took copious notes to capture the verbatim description. Using the SHOWeD mnemonic, a few participants also did a "freewrite" in which they wrote down their thoughts about their photographs. After the small group discussions, participants and facilitators reconvened. Several participants from each group described one of their images to the entire large group. Forty participants attended each of the last workshops.

At the last workshop, the county's Director of Family, Maternal and Child Health also presented each participant a Certificate of Appreciation. Workshop facilitators requested and received permission from participants to photograph the workshop. Each participant filled out a consent form specifying that any of his or her photographs could be reprinted as part of the project; that only specific photographs could be reprinted; or that none of his or her photographs be reprinted.

The second Picture This series of workshops were held in west county. Twenty individuals participated; 8 participants were youth between the ages of 1619 years, and 12 were adults between 21 and 50 years. All but two of the participants attended all three sessions. Of the two who for family reasons were not able to attend all three, both sent in their cameras. Work- shop facilitators followed the same format as was used in the first three sessions, with the addition during the initial slide show of some photographs taken by participants in the first Picture This group.

\section{PICTURE THIS PHOTOVOICE FINDINGS}

Participants' perceptions of what would most improve family, maternal and child health differed from those generated by health department personnel. As a result of categorical funding by federal and state MCH sources, health department staff have designed traditional maternal and child health interventions to focus upon improving entry into prenatal care, as well as to reduce low birth weight births and infant mortality, enhance quality of prenatal care, eliminate family and domestic violence, prevent teen pregnancies, and address issues of tobacco and substance use during pregnancy. By contrast, two major themes repeated by participants of all ages were the need for safe recreation for children, and the need to improve the broader community environment within county neighborhoods.

The first theme, the need for safe recreation for children, emerged as some participants photographed 1) roadside crosses where children have been killed; 2) inadequate posting of neighborhood stop signs specifically near elementary schools; and 3) an English-Spanish park sign that read, "This area is not maintained by the city of Antioch. Enter at your own risk." One woman photographed her children and nephews playing at the park where this sign was posted and explained that she worried about the children finding hypodermic needles in the sand box area (26). Adolescent and adult participants photographed unusable basketball hoops and abandoned playgrounds. Another participant, who showed her nephew in his little league uniform, described with pride how happy her nephew was to belong to a team and how important it was to the family that the child had some kind of supervised recreational opportunities in which to participate.

The second theme, the need to improve the broader community environment within county neighborhoods, emerged as residents photographed landlords' neglect of property; graffiti; trash; and the closure of a hospital that provided inadequate health services for low-income people. One resident from the eastern section of the county photographed oil refineries in his neighborhood and relayed his fears about the dangers of these refineries. Several 
adolescent participants took photographs from their schools and exposed poorly maintained bathrooms, filthy water sinks, and dangerous walkways. Approximately one-quarter of participants photographed trash; although none of these individuals previously knew one another, some photographed the same trash in a particular neighborhood.

Residents also photographed neighborhood assets and resources, such as reclaimed parks, bright murals, and places where debris had been cleaned out. One who photographed a neighborhood park wrote:

\begin{abstract}
This is a beautiful site with lots of flowers. It used to be a dumping place, but people cleaned it up and grew flowers. The bars are there to protect the flowers and the murals, planted and created by youth. It used to be such a dirty place. If we keep the environment clean, we will have better health. We should use this place as an example. This place exists because there are people who care about their surroundings and are willing to clean up around them. The Iron Triangle neighborhood organized this.
\end{abstract}

Participants told powerful stories. One photograph, showing a wheelchair and medical supplies belonging to an elderly person being cared for at home by her son (the photographer), resonated with other participants who either knew others also caring for elderly relatives in the home or anticipated that they would be doing so in the future. Or again, one adolescent shared a photograph of her best friend holding her new baby. In the image, the young woman looks happy and contented, and the baby looks calm and healthy. The photographer explained that her friend, battered by the father of the baby, had to move home to live with her parents. Other participants talked about teenage pregnancy as a result of the sharing of this photograph, and many expressed concern about the rise in teen mothers, battery and abuse of these young women, and their concerns about the welfare of the children.

Participants were creative in thinking about how they wished to photograph family, child, and maternal health issues. One young woman photographed a tree silhouetted against the sky to depict neighbors' narrow attitudes towards children with disabilities. "You can see the isolation. Solitude. The neighbors are ignorant; they don't want the kids there. They see them as sick." Taking self-portraits as well as pictures of family, friends, and pets, participants indicated that they did not intend to share or discuss these photographs with other group members, but would show these images to a health department staff person as a way of sharing more about themselves and their lives.

\section{RESULTS OF A HEALTH DEPARTMENT'S USE OF PHOTOVOICE METHODOLOGY}

The photographs and stories gathered through the Picture This project supplemented the health department's quantitative data that was used to determine $\mathrm{MCH}$ objectives for the 5-year work plan. In selecting key work plan objectives, for example, $\mathrm{MCH}$ staff took into consideration participants' concerns about the need for after school programs for youth with a special focus on community service projects.

The Picture This project has energized and mobilized some community residents to take action in their communities. Some participants have started working to see that the parks are cleaned. Others have mounted a campaign to keep a local recreation program open. Several participants have asked to be part of an $\mathrm{MCH}$ advisory committee to provide the health department with ideas, suggestions, and direction for future programs. The project has helped to identify a cadre of community people to contribute to the health department's outreach, community organizing, community health assessment, and program evaluation long after the formal project period has ended.

Following the two Picture This sessions, county health department staff chose several venues to disseminate participants' photographs and stories, including a community health fair presentation, an exhibition at the health department, and an invited exhibition at the statewide Maternal and Child Health Conference at the state capitol. Plummer notes that "Stories are not just practical and symbolic actions; they are also part of the political process" (27). The photovoice methodology formalizes the making of stories, vivified with images, produced by community people to inform health planning. For its creativity, contribution to resource building, and overall impact, the Picture This project has been recognized with a statewide $\mathrm{MCH}$ Special Achievement Award in California.

\section{DISCUSSION}

\section{Strengths}

We describe here how photovoice may contribute to family, maternal, and child health planning in ways not addressed by other approaches.

First, photovoice serves as a way of gaining community input from people directly affected by $\mathrm{MCH}$ programs, systems, and policies. The need for "real 
people" to participate in defining $\mathrm{MCH}$ questions, problems, assets, and solutions, has been recognized broadly and institutionally at the county, state, and federal levels, as well as by university researchers and practitioners. The Public MCH Program Functions Framework notes that an essential public health service to promoting US maternal and child health is mobilize families and the general public, in partnership with policy makers and providers, to identify and solve maternal and child health problems (28; emphasis added). Similarly, Wagner observes that "WHO has been working to correct the balance (in clinical and public health approaches) by expanding the body of knowledge in perinatology recognized as authoritative, opening it up to include, in addition to the viewpoint of clinicians, the viewpoint of midwives, scientific researchers, public health professionals, and women-at large" (29). Photovoice offers MCH workers one strategy with which to operationalize these ideals. The methodology offers a novel way to tap the creativity, lore, and strengths of community people from diverse cultural subgroups regardless of their formal educational background.

The second contribution relates to the mandate of needs assessments for $\mathrm{MCH}$ programs every 5 years; photovoice creates an opportunity for $\mathrm{MCH}$ staff to complement or enhance quantitative assessment data with grassroots visual and narrative data. When conducting interview or questionnaire surveys, $\mathrm{MCH}$ staff perceived that respondents were often limited by how questions were framed. These surveys sometimes reflected not so much constituents' specific concerns as MCH staff's assumptions and judgments. Photovoice gave MCH staff an opportunity to learn about perceptions of family, maternal, and child health issues through constituent-produced information with a human face. By looking at the cumulative body of photographs and stories, $\mathrm{MCH}$ staff sought to use photovoice in conjunction with other survey and data gathering instruments to add to the overall community portrait.

Third, even the most experienced MCH staff may learn from the body of images and stories generated through photovoice. Health department staff reported that they were invigorated with a new understanding of community issues as defined by the people they serve. For example, the project focused attention upon the lack of safe and supervised recreation facilities and activities for children and youth; and pointed staff in the direction of investing efforts in the design, maintenance, and promotion of recreational facilities and activities. MCH staff noted that the most signif- icant concerns documented by participants extended beyond archetypical maternal and child health categories. Put another way, participants chose to define family, maternal, and child health in terms of community health, as when highlighting conditions of safety and well-being for themselves and their children.

Fourth, photovoice may enhance the quality of advocacy conducted by $\mathrm{MCH}$ staff by equipping them with narrative-driven policy and program recommendations, as was reported by health department staff in our project. In this way, as Declercq notes, "Individuals still profoundly shape the policy-making process, particularly in the early stages, and, in health care, their personal experiences with the system matter" (30). For example, one man photographed a closed community hospital. He sought to document inadequate health services for low-income people. The photograph, and other complaints, have prompted the county to improve care at its city clinic. On a more general and related level, health department leaders Pierce and Blackburn have noted the "difficulty explaining to public officials and local officials what public health does" (31); photovoice can serve as a tool to educate participants and audiences alike about what public health does and, within the parameters of its emphasis on prevention and health promotion, what it ought to do.

Finally, photovoice may also serve to foster a sense of community and place among participants. Initially strangers prior to the workshops, participants found that they could provide palpable support to one another by giving advice about county health resources, and that concerns about certain local issues transcended their own generational, neighborhood, and ethnic differences.

\section{Limitations}

We note several methodological limitations. First, information gleaned through photovoice, like all information, is inherently subject to dilemmas of interpretation and representation; who controls or contributes to the public presentations of participants' photographs and stories can determine the purposes to which they will be put.

Photovoice is not intended to be a methodology in which an entire body of visual data is exhaustively analyzed in the social scientific sense. $\mathrm{MCH}$ researchers wishing to approach visual data from such a positivist epistemology might see, for example, Collier 
and Collier's landmark text, Visual Anthropology: Photography as a Research Method, which begins to explore how the researcher can systematically evaluate visual content (32). As a participatory methodology, photovoice requires a new framework and paradigm in which participants drive the analysisfrom the selection of their own photographs that they feel are most important, or simply like best, to the "decoding" or descriptive interpretation of the images $(1,2)$. The authors and $\mathrm{MCH}$ staff have done their best to represent faithfully themes identified by participants in consensus-based group discussions.

Second, the ideas and perceived needs articulated were those of the individuals who chose to participate, take photographs, return to the second and third sessions, and share their photographs and stories. The issues that were raised were those of this particular group of individuals at this particular time, and might be different with a different group of participants from other regions of the county. As with clinical trials relying upon the recruitment of volunteers, photovoice participants by definition may not be representative of their broader cohort.

Third, we cannot determine the extent to which participants may be more likely to show certain types of visual concerns and less often portray topics less easily photographed. However, as with the examples given earlier illustrating creativity in what they photographed, we observed that some participants were highly inventive and motivated to couple visual metaphor with narrative to convey meaning.

Fourth, the proscribed contact $\mathrm{MCH}$ staff had with participants made it difficult to understand fully the extent to which the participants may have directly benefited from the project, such as by an increased sense of political efficacy or self-esteem. In addition, for most photovoice projects, sample sizes may be too small for pre- and postworkshop surveys to lend themselves to statistical analyses of outcomes. Also, the health department found that with relatively few staff, it was challenged to follow up with participants who had self-identified as willing and available to assist county staff in planning and developing family, maternal, and child health programs and priorities.

Finally, policy change is often slow and incremental, and data of all kinds are needed by policy makers to inform a viewpoint and frame a persuasive argument. It may be difficult to quantitatively demonstrate the degree to which a photovoice project contributed to improved program or policy outcome in a defined time period.

\section{CONCLUSION}

The practice of maternal and child health is anchored in the understanding that we as professionals have identified and understood the concerns of those whom we serve. Through the photovoice methodology, $\mathrm{MCH}$ program staff enlists these individuals as full participants in identifying and sharing knowledge about their concerns. While their perspectives may differ from those reflected in well-established indicators of maternal and child health, they are vital to keeping the interests of community people at the center of our planning and evaluation efforts. Stepping outside conventional disciplinary and professional boundaries may make our jobs more challenging by helping to identify new, previously overlooked, or unidentified concerns and assumptions. However, the foremost concerns of mothers, children, and families should be a basic element of maternal and child health promotion practice. We suggest photovoice play a role in this larger vision.

\section{ACKNOWLEDGMENTS}

Picture This Photovoice was supported, in part, by Contra Costa Health Services. The authors are grateful to Wendel Brunner, Public Health Director for CCHS for providing ongoing support for this project, and Beth Tsoulos, Purnima Manghanani, and staff of the Family Maternal and Child Health Programs for valuable assistance. We thank the Editor and reviewers for their helpful comments. We are indebted to the Picture This participants for their insights and ideas.

\section{REFERENCES}

1. Wang CC, Burris M. Photovoice: Concept, methodology, and use for participatory needs assessment. Health Educ and Behav 1997;24(3):369-87.

2. Wang CC. Photovoice: A participatory action research strategy applied to women's health. J Women's Health 1999;8(2):18592.

3. Wang C, Burris M, Xiang YP. Chinese village women as visual anthropologists: A participatory approach to reaching policymakers. Soc Sci Med 1996;42:1391-1400.

4. Freire P. Pedagogy of the oppressed. New York: Seabury, 1970.

5. Wallerstein N, Bernstein E. Empowerment education: Freire's ideas adapted to health education. Health Educ $Q$ 1988;15(4):379-94.

6. Smith DE. The everyday world as problematic. Boston: Northeastern University Press, 1987.

7. Ewald W. Portraits and dreams: Photographs and stories by children of the Appalachians. New York: Writers and Readers 1985. 
8. Ewald W. I dreamed I had a girl in my pocket. NewYork: DoubleTake Books, 1996.

9. Hubbard J. Shooting back: A photographic view oflife by homeless children. San Francisco, CA: Chronicle Books, 1991.

10. Spence J. Cultural sniping: The art of transgression. London: Routledge, 1995.

11. Wolper A. Making art, reclaiming lives: The artist and homeless collaborative. In: Felshin N, editors, But is it art? The spirit of art as activism. Seattle, WA: Bay Press. 1995:251-82 (chapter 9).

12. Wang C, Burris M. Empowerment through photo novella: Portraits of participation. Health Educ Q 1994;21(2):171-86.

13. Wang C, Yuan YL, Feng ML. Photovoice as a tool for participatory evaluation: The community's view of process and impact. J Contemp Health 1996;4:47-9.

14. Wang CC, Wu KY, Zhan WT, Carovano K. Photovoice as a participatory health promotion strategy. Health Promot Int 1998;13(1):75-86.

15. Bowers AA. People with serious mental illnesses using photovoice: Implications for participatory research and community education. Paper presented at the American Public Health Association Annual Meeting, Chicago, 1999.

16. Wang CC, Cash J, Powers LS. Who knows the streets as well as the homeless?: Promoting personal and community action through photovoice. Health Promot Pract 2000;1(1):81-89.

17. Killion CM, Wang CC. Linking African American mothers across life stage and station through photovoice. J Health Care Poor Underserved 2000;11(3).

18. May M. Sounding the alarm: East bay's teenage 'Town Criers' use cameras to bring new focus to AIDS. San Francisco Chronicle November 25, 2001, A1.

19. Lopez EDS. Quality of life needs among rural African American breast cancer survivors from eastern North Carolina: Blending the methods of photovoice and grounded theory. $\mathrm{PhD}$ Dissertation, University of North Carolina at Chapel Hill, 2002.

20. Strack RW, Magill C, McDonagh K. Engaging youth through photovoice. Health Promot Prac 2003;5(1):49-58.
21. Wang CC, Morrel-Samuels S, Hutchison P, Bell L, Pestronk RM. Flint photovoice: community-building among youth, adults, and policy makers. Am J Public Health 2004; forthcoming.

22. Maternal and Child Health Branch, California Department of Health Services. California Maternal and Child Health County Data Book. Martinez, California, January, 1999.

23. Wang CC, Redwood-Jones Y. Photovoice ethics. Health Educ Behav 2001;28(5):560-72.

24. Minkler M, Hancock T. Community-driven asset identification and issue selection. In: Minkler N., Wallerstein N, editors, Community-based participatory research for health. San Francisco: Jossey-Bass, 2003: 135-54 (chapter 7).

25. Kretzmann J, McKnight J. Building communities from the inside out: A path toward finding and mobilizing a community's assets. Evanston, IL: Center for Urban Affairs and Policy Research, 1993.

26. Spears L. Picturing concerns: The idea is to take the messages to policy-makers and to produce change. Contra Costa Sunday Times April, 1999.

27. Plummer K. Documents of life: An introduction to the problems and literature of a humanistic method. London: Allen and Unwin, 1983.

28. Grason HA, Guyer B. Public MCH program functions framework: Essential public health services to promote maternal and child health in America: State applications. Baltimore, MD: Child and Adolescent Health Policy Center, Johns Hopkins University, 1995.

29. Wagner M. The public health versus clinical approaches to maternity services: The emperor has no clothes. J Public Health Policy 1998;19(1):25-33.

30. Declercq E. "Changing childbirth" in the United Kingdom: Lessons for US health policy. J Health Politics, Policy, and Law 1998;23(5):833-59.

31. Pierce JR, Blackburn CP. The transformation of a local health department. Public Health Rep 1998;113, 152-59.

32. Collier J, Collier M. Visual anthropology: Photography as a research method. Albuquerque: University of New Mexico, 1986. 